\title{
Once daily levocetirizine for the treatment of allergic rhinitis and chronic idiopathic urticaria
}

\author{
E Nettis' \\ G F Calogiuri² \\ E Di Leo' \\ F Cardinale ${ }^{3}$ \\ L Macchia' \\ A Ferrannini' \\ A Vacca ${ }^{1,4}$ \\ 'Section of Allergology and Clinical \\ Immunology, Department of Internal \\ Medicine and Infectious Diseases; \\ 24th Pneumology Department, \\ Pneumologic Hospital A Galateo, San \\ Cesario di Lecce, Italy; ${ }^{3}$ Department \\ of Biomedicina dell'Età Evolutiva, \\ Pediatrics Unit "S Maggiore"; \\ ${ }^{4}$ Department of Internal Medicine \\ and Clinical Oncology, University \\ of Bari Medical School, Bari, Italy
}

Correspondence: Eustachio Nettis

Cattedra di Allergologia ed Immunologia

Clinica, Università degli Studi di Bari,

Policlinico, Piazza Giulio Cesare, II

70124 Bari, Italy

Tel +390805592821

Fax +390805593576

Email e.nettis@allergy.uniba.it

\begin{abstract}
Levocetirizine is the pharmacologically active enantiomer of cetirizine. It is a potent histamine $\mathrm{H}-1$ receptor antagonist with anti-inflammatory and antiallergic properties. The review analyses the levocetirizine's properties in terms of safety and efficacy both in allergic rhinitis and urticarioid syndromes.
\end{abstract}

Keywords: allergic rhinitis, chronic idiopatic urticaria, levocetirizine

Levocetirizine (R-cetirizine), or (R)-[2-[4-[(4-chlorophenyl)phenylmethyl]1-piperazinyl]ethoxy]acetic acid dihydrochloride is the pharmacologically active enantiomer of cetirizine, and is a potent histamine $\mathrm{H}-1$ receptor antagonist. ${ }^{1}$ Cetirizine consists of a racemic mixture of R- and S-cetirizine. The two enantiomers differ as to pharmacological activity, bond affinity to the H-1 receptor, and dissociation constant. Various studies agree in attributing all pharmacological activity, higher bond affinity, and longer dissociation half-life to R-cetirizine. ${ }^{2}$ These characteristics make levocetirizine an excellent pseudo-irreversible antagonist of the $\mathrm{H}-1$ receptor, and one that is not as easily displaced by histamine as cetirizine on the $\mathrm{H}-1$ receptor in vivo. The high power and specificity of levocetirizine as inverse agonist for the $\mathrm{H} 1$ receptor $^{3}$ have been demonstrated both at the level of endothelial cells and of smooth muscle fibrocells of blood microcirculation. ${ }^{4}$ On these sites the antagonism of histamine is responsible for the inhibition of the increase in vascular permeability and vasodilation. Inhibition of edema formation and mucus secretion represent the result of levocetitizine effects on skin and respiratory mucosa, respectively. These pharmacological actions underlie the therapeutic effect of levocetirizine in urticaria and rhinitis.

Levocetirizine also has several other pharmacological effects partially related to its antagonism on the H-1. T lymphocytes, dendritic cells and lung macrophages express the histamine $\mathrm{H}-1$ receptor on their cell surface which induces the expression of activation molecules and the synthesis of cytokines and chemokines with proinflammatory effects when activated. ${ }^{5}$ Triggiani and colleagues have recently demonstrated that levocetirizine can inhibit the synthesis of IL-6 from human lung macrophages and histamine-induced production of IL-8 by dendritic cells. ${ }^{6}$

The inhibiting effects of levocetirizine have also been studied on keratinocytes, where it blocks the secretion of chemokines and GM-CSF. ${ }^{7}$ Additionally, recent studies have shown that levocetirizine reduces the expression of activation molecules (CD134 and ICAM-1) and of a transcription factor involved in the differentiation of Th2 lymphocytes (GATA-3). ${ }^{8}$

The inhibition of the NF- $\mathrm{KB}$ transcription factor complex induced by levocetirizine suppresses the endothelial production of eotaxin, IL- $1 \beta$, TNF- $\alpha$ and VCAM-1 stimulated by histamine. ${ }^{9}$ 
Lastly, levocetirizine significantly inhibits both eotaxininduced eosinophil transendothelial migration ${ }^{10}$ and endothelial adhesion, ${ }^{11}$ and modulates the release (at a concentration of $1 \mathrm{nM}$ ) of proinflammatory cytokines such as IL-1 $\beta$ and IL-7 by liposaccharide-activated eosinophils, at the same time increasing the tissue inhibitors of metalloproteinase-1 and -4 and of matrix metalloproteinase- $9 .{ }^{12}$

The latter anti-inflammatory and antiallergic properties are expressions of other pharmacological activities of levocetirizine ${ }^{9}$ not strictly correlated to its receptor antagonist action. Levocetirizine has been shown to have these properties at plasma concentrations between 10 and $500 \mathrm{nM},{ }^{9,10}$ which is the range comprising the molecule's plasma concentration $(\sim 400 \mathrm{nM})$ during a standard treatment at a dose of $5 \mathrm{mg} .{ }^{13}$ Other second generation antihistamines showed the same effects that were present only in vitro and at pharmacological concentrations unattainable in vivo. ${ }^{14}$

An innovative concept, which has emerged from the latest studies on levocetirizine, is that there may be a positive interaction between the anti-inflammatory effects and $\mathrm{H}-1$ receptor antagonism. This hypothesis is based on the observation that $\mathrm{H}-1$ is a highly dynamic receptor, whose expression on antiinflammatory cells may be rapidly modulated (increased or inhibited). Recent data indicate that some cytokines (TNF- $\alpha$, IL-8, IL-13) or growth factors (GM-CSF) can enhance the $\mathrm{H}-1$ receptor's expression on monocytes, macrophages and dendritic cells. ${ }^{15,16}$ By inhibiting the production of the cytokines and growth factors mentioned above, as well as the recruitment of the cells involved in allergic immunophlogosis, the pharmacological blockage of H-1 and H-2 cell receptors by levocetirizine might modify the pathogenesis and clinical evolution of allergic diseases. ${ }^{16}$ If verified in vivo, this hypothesis could provide the basis for an effective synergy between antiinflammatory action and $\mathrm{H}-1$ receptor antagonism.

\section{Safety of use of levocetirizine}

The pharmacokinetics of levocetirizine present a linear correlation with the administered dose, are not time dependent, and exhibit little variability among different subjects. Administered orally, levocetirizine is absorbed quickly and broadly; its bonding to plasma proteins is $95 \%$ and its distribution volume is low $(0.31 / \mathrm{kg})$, which, for a $\mathrm{H}-1$ receptor antagonist, represents a real advantage. ${ }^{17}$ Because its metabolism is limited, its pharmacokinetics are poorly modified by concomitant intake of other drugs. It is mainly excreted through the urine by glomerular filtration and active tubular secretion; therefore, it is recommended to prolong the time between doses in patients with chronic renal failure.
In regards to its safety profile, no negative effects on alertness, reaction abilities, or ability to drive vehicles have emerged from the clinical studies reported in the literature after one or more doses of levocetirizine at the recommended dosage of $5 \mathrm{mg} /$ day. ${ }^{18-22}$ Verster and colleagues ${ }^{18}$ have evaluated the effects of treatment with various antihistamines on memory, psychomotor abilities and mood state. Two antihistamines were examined: levocetirizine $(5 \mathrm{mg})$ and diphenhydramine $(50 \mathrm{mg}$ ) vs placebo, administered at three different times once daily on four consecutive days. The study group consisting of 48 healthy volunteers ( 24 males and 24 females) underwent a series of laboratory tests (verbal learning test, Sternberg memory test, pursuit test, divided attention test) three hours after the first dose (acute phase) and at the end of the study, ie, on the fourth day (chronic phase). The results demonstrated that a single dose or repeated doses of levocetirizine had no modification on memory, attention and motor skills, whereas diphenhydramine induced a significant reduction in attention and motor skills as early as after the first dose. ${ }^{18}$

In the same group, an assessment of the effects on driving skills showed not statistically significant changes in the group treated with levocetirizine compared with placebo, unlike the results observed with diphenhydramine. ${ }^{19}$

The absence of sedative effects has been confirmed by two other double-blind, placebo controlled clinical studies conducted to evaluate the effects on cognitive and psychomotor functions, in groups of 20 and 19 subjects respectively, of treatment with levocetirizine ${ }^{20,21}$ or first-generation antihistamines like promethazine ${ }^{20}$ and diphenhydramine ${ }^{21}$ and second-generation antihistamines (cetirizine and loratadine). ${ }^{20}$

A study by Potter ${ }^{22}$ reports the absence of significant adverse reactions during a six-week treatment with levocetirizine at $5 \mathrm{mg} /$ day. In both two examined groups (in treatment with levocetirizine and placebo) was reported at least one adverse reaction in similar percentages: $60.0 \%$ and $68.1 \%$, respectively. ${ }^{22}$ The most frequent adverse reaction was headache ( $34.7 \%$ both for levocetirizine and for placebo), influenza-like symptoms (16.7\% and $13.9 \%$, respectively), high respiratory tract infections $(6.7 \%$ and $9.0 \%$, respectively) and drowsiness $(6.0 \%$ and $2.8 \%$, respectively). ${ }^{22}$ Apart from the cases of drowsiness, no reduction of the memory and psychomotor functions has been demonstrated. ${ }^{20}$ In one subject there was an increase in alanine aminotransferase, correlated with the drug, which regressed spontaneously after nine days. ${ }^{22}$ During this study there were no cases of increased electrocardiogram (ECG) QT interval. ${ }^{22}$ The absence of cardiotoxic effects of levocetirizine has been recently 
confirmed by a study conducted on 52 healthy subjects treated with $5 \mathrm{mg}$ and $30 \mathrm{mg}$ under dynamic monitoring according to Holter method in the 24 hours following the dose. ${ }^{23}$

A study conducted in Germany on 17,638 subjects (24) confirmed the good tolerability of levocetirizine with a rate of $1.6 \%$ of mild or moderate adverse reactions reported during administration (fatigue, headache, gastrointestinal disorders, dizziness, dry mouth). These adverse events compromised the subjects' well being to a modest extent.

\section{Efficacy of levocetirizine in allergic rhinitis}

Allergic rhinitis is a high-prevalence chronic respiratory disease with a negative impact on the subjects' quality of life, work activities, productivity or school performance, as well as on healthcare costs. Because of its benign nature, the importance of this condition is often underestimated.

Levocetirizine is an antihistamine molecule that has been shown by various studies to have an effective and immediate action in reducing eye and nose symptoms of seasonal as well as perennial rhinitis. Its efficacy profile in the chronic treatment of rhinitic patients has been demonstrated to be better than other second generation antihistamines, including desloratadine and fexofenadine.

An initial two-week randomized double-blind placebo-controlled study on 470 patients subdivided into three groups treated with $2.5,5$, and $10 \mathrm{mg}$ levocetirizine, respectively, demonstrated that levocetirizine is effective in reducing the symptoms measured using the Total Four-Symptom Score: T4SS (nasal pruritus, ocular pruritus, rhinorrhea, and sneezing) in patients with seasonal rhinitis compared with placebo, and that the effect is dose-dependent. ${ }^{25}$ Based on this study, it has been concluded that the $5 \mathrm{mg}$ /day dosage presented the best risk-benefit ratio for the treatment of nose and eye symptoms in seasonal allergic rhinitis. ${ }^{25}$

These results have been confirmed and extended in a multicenter, randomized, double-blind placebo-controlled study on 294 patients with perennial rhinitis. ${ }^{26}$ A scale with four values of increasing severity, from 0 to 3 , was used to assess the five symptoms (rhinorrhea, nasal pruritus, ocular pruritus, sneezing, nasal congestion). ${ }^{26}$ Out of 294 randomized patients, 144 were treated with placebo and 150 with levocetirizine at dosages of $5 \mathrm{mg}$ /day for six weeks. Improvements in T4SS vs placebo were $86 \%$ in the first week and $47 \%$ at the end of the study. ${ }^{26}$ This study has also highlighted a significant effect of levocetirizine on improvement of nasal congestion, one of the most annoying among the symptoms associated with rhinitis and generally poorly responsive to antihistamine treatment. ${ }^{26}$

The efficacy of $5 \mathrm{mg}$ levocetirizine has been compared with that of $10 \mathrm{mg}$ loratadine in dust mites allergic patients by performing a challenge test in the Vienna Challenge Chamber, a special facility where patients are exposed to pre-determined amounts of allergen, allowing an accurate evaluation of drug effects on the symptoms that appear after the allergen exposure. ${ }^{27}$ In the double-blind, placebo-controlled cross-over study, 39 patients received the challenge test through a six-hour exposure to dust mite allergens on two consecutive days. ${ }^{27}$ The drugs were administered after two hours of exposure. Symptom severity was assessed using the Complex Symptom Score (CSS), consisting of the sum of the individual scores for rhinorrhea, nasal pruritus and sneezing. ${ }^{27}$ The percentage of patients with a CSS reduction of at least $20 \%$ was $43 \%$ for the placebo group, $66.7 \%$ for loratadine, $83.8 \%$ for levocetirizine, and the clinical improvement was achieved within 60 minutes after receiving levocetirizine, vs 90 minutes for loratadine. ${ }^{27}$

A comparative study vs desloratadine (the active enantiomer of loratadine), conducted on 23 subjects, also confirmed the substantially higher rapidity of levocetirizine's pharmacological action after a single dose administration. ${ }^{28}$ In addition, levocetirizine showed a more protective effect, when compared to desloratadine, in patients with seasonal rhinitis submitted to the specific nasal challenge test. ${ }^{29}$

The effect of levocetirizine on nasal obstruction, compared to desloratadine, has also been recently confirmed by Ciprandi and colleagues ${ }^{30}$ in a pilot study conducted on 30 subjects with seasonal allergic rhinitis. The enrolled patients were assigned to randomized treatment with levocetirizine, desloratadine or placebo for two weeks and then assessed using a modified TSS, including nasal congestion, as well as rhinomanometry to determine the presence of inflammatory infiltrate and cytokine secretion in the nasal secrete. The results have shown that only levocetirizine, and not desloratadine, is able to improve nasal air flows and to reduce significantly the IL-4 and IL-8 production. ${ }^{30}$

A comparison of the beginning and duration of the pharmacological action and clinical efficacy of levocetirizine vs desloratadine had been previously conducted in another randomized, double-blind, parallel-group clinical study based on the model known as Environmental Exposure Unit (EEU), a special chamber that allows simultaneous exposure of up to 160 people at a predetermined level of pollen granules. ${ }^{31}$ Out of 373 randomized patients, 141 were assigned to the cetirizine group, 140 to the desloratadine group, and 92 to the 
placebo group. The patients were exposed to Ambrosia pollen in the EEU for seven hours on Day 1 and for six hours on Day 2; the symptoms were measured every 30 minutes. Levocetirizine was found to achieve a significant symptom reduction as early as the first hour, compared with three hours required for desloratadine to act; additionally, 24 hours after the first dose and just before receiving the second dose, symptom reduction was significantly higher in the patients treated with levocetirizine compared to subjects that assumed desloratadine. Both active treatment groups showed symptom improvement compared to the placebo-group. ${ }^{31}$

In a comparative study vs fexofenadine at a dosage of $120 \mathrm{mg}$, levocetirizine at a dosage of $5 \mathrm{mg}$ proved to have a more potent and long lasting action in reducing rhinitic symptoms 22-28 hours after the dose. Levocetirizine's speed of action and clinical efficacy resulted in a higher degree of patient satisfaction with the treatment. ${ }^{32}$

Another study compared levocetirizine's efficacy against fexofenadine in reducing nasal congestion symptoms. ${ }^{33}$ The assessment was performed using infrared facial thermography, a noninvasive technique for the measurement of temperature changes in the nasal region. Because vasodilation and allergic immunophlogosis are associated with an increase in skin temperature in the nasal region, this technique allows the objective viewing of the patient's clinical improvement in terms of reduced blood flow and nasal congestion..$^{33}$ The double-blind, controlled, cross-over study assessed baseline thermography vs the value measured 20 minutes after nasal challenge with histamine in 30 healthy subjects. The thermography was repeated in all 30 volunteers two hours and 24 hours after they had received $5 \mathrm{mg}$ levocetirizine, $120 \mathrm{mg}$ fexofenadine or placebo. ${ }^{33}$ While the thermography confirmed the efficacy of both antihistamine drugs in reducing immunophlogosis, as demonstrated by the significant reduction in perinasal skin temperature compared with placebo two hours after administration, the measurement performed at 24 hours demonstrated that levocetirizine produces a more marked extension of the decongested nasal areas and a more prolonged nasal temperature reduction than fexofenadine. ${ }^{33}$

As suggested by the recent Allergic Rhinitis and its Impact on Asthma (ARIA) Guidelines,${ }^{34}$ a new classification of allergic rhinitis in intermittent or persistent form has been made according to symptom duration and severity. In persistent rhinitis the symptoms are present for more than four days a week and for more than four weeks a year. ${ }^{34}$

The results of XPERT (Xyzal in Persistent Rhinitis Trial), a 6-month multicenter, double-blind, placebo controlled study conducted on 551 patients with persistent allergic rhinitis, both perennial and seasonal, treated with levocetirizine and placebo confirmed that levocetirizine improves significantly not only the clinical symptoms assessed by the TSS, but also the quality of life, as measured by the RQLQ (Rhinoconjuntivitis Quality of Life Questionnaire). ${ }^{35}$ After six months, levocetirizine improved the quality of life of allergic patients by more than $30 \%$ compared to placebo. ${ }^{35}$ The study also demonstrated a reduction of the overall cost of the disease as calculated throughout the study period. ${ }^{35}$ A more detailed analysis proved that levocetirizine helped achieve a $43 \%$ saving on the social cost of persistent allergic rhinitis, equal to approximately $€ 153$ per month per patient. In regards to employed patients, the saving was approximately $€ 65$ per month in terms of work days lost because of allergic rhinitis. ${ }^{36}$

Lastly, thanks to the widespread implementation of the ARIA guidelines ${ }^{34}$ and the recent scientific evidence of the role played by the $\mathrm{H}-1$ receptor in allergic immunophlogosis, ${ }^{16}$ levocetirizine might soon be added to the traditional therapies for the treatment of atopic bronchial asthma, as it has already demonstrated a protective effect against adenosine monophosphate-induced bronchospasm in 15 subjects with allergic asthma. ${ }^{37}$

\section{Efficacy of levocetirizine in urticarioid syndromes}

Acute and chronic urticaria is one of the major diagnostic and therapeutic problem in allergologic field. The etiological diagnosis of urticaria is not always possible, and in fact it is formulated in less than $50 \%$ of the cases; moreover, this condition is often a symptom of systemic diseases of various natures (infective, metabolic or neoplastic). Consequently, the treatment of these patients, especially of those with chronic idiopathic urticaria, is particularly complex, as the pathogenesis of this clinical variant includes self-immune mechanisms ${ }^{38}$ with activation of tissue factors of coagulation. ${ }^{39,40}$

An initial study on 18 healthy volunteers was conducted on a model of allergic skin reaction after histamine prick test at a concentration of $100 \mathrm{mg} / \mathrm{mL} .{ }^{41}$ The areas, expressed in $\mathrm{mm}^{2}$, of both the wheal and the surrounding flare were calculated at different times after the test $(0.5,1,2,4,6,8$, 10,12 , and 24 hours). Levocetirizine demonstrated higher efficacy and more prolonged action in inhibiting histamineinduced wheal formation than ebastine $(10 \mathrm{mg})$, fexofenadine $(180 \mathrm{mg})$, mizolastine $(10 \mathrm{mg})$, and loratadine $(10 \mathrm{mg}){ }^{41}$

A comparison with cetirizine also showed that a $2.5 \mathrm{mg}$ once daily oral dose of levocetirizine inhibited 
the histamine-induced wheal formation almost entirely in 18 normal subjects. ${ }^{42}$ The inhibiting effect was comparable to that achieved with $5 \mathrm{mg}$ of cetirizine. The effect of levocetirizine began after approximately one hour, reached its peak six hours after administration and persisted for 28 hours. $^{42}$

Subsequent studies confirmed the blocking effect of levocetirizine on the histamine-induced skin reaction, and demonstrated its greater efficacy compared with desloratadine. ${ }^{28,43,44}$

Levocetirizine induces a quantitatively greater reduction of histamine wheal in a higher percentage of patients for a longer time than desloratadine. ${ }^{44}$

A recent investigation conducted on 18 allergic patients submitted to aeroallergen skin prick tests (SPT) measured the surface, in $\mathrm{mm}^{2}$, of the SPT-induced wheal and flare before and after the administration of placebo, desloratadine and levocetirizine. ${ }^{45} \mathrm{~A}$ serum and receptor assay of both antihistamine drugs was also performed. The study provided evidence that levocetirizine achieved stronger and more effective $\mathrm{H}-1$ receptor blockage than desloratadine, although the latter was found in higher concentration at skin level. ${ }^{45}$

However, given the complexity of chronic idiopathic urticaria, the doubt remained whether levocetirizine would prove equally effective.

In an initial double-blind, placebo controlled study, levocetirizine-although at different dosages $(2.5,5$, and $10 \mathrm{mg}$ )-produced a significant improvement in clinical parameters (pruritus intensity and duration, wheal number and size) and quality of life score, as determined using the Dermatology Life Quality Index (DLQI) ${ }^{46}$ in 258 patients with chronic idiopathic urticaria. The therapeutic effect of levocetirizine was significant when compared to placebo as early as the first week of treatment, and persisted throughout the entire duration of the study (4 weeks) even at the minimum dosage of $2.5 \mathrm{mg} .{ }^{46}$

Subsequent studies have confirmed levocetirizine's speed of action and efficacy in 166 patients with chronic urticaria. ${ }^{47}$ The objective was to measure the change induced by levocetirizine on itching severity one week and four weeks after treatment, according to a scale from 0 (no itching) to 3 (more than 6 hours of itching per day), and to evaluate the quality of life through the DLQI. ${ }^{47}$ During the first week, treatment with $5 \mathrm{mg}$ levocetirizine led to a marked improvement of itching severity and a reduction in wheal number and size compared with placebo. These effects remained stable throughout the three following weeks. ${ }^{47}$
During treatment, the quality of life (DLQI) score improved in both groups, but more noticeably in the group treated with levocetirizine. ${ }^{47}$ The results of the study on treatment impact on cost and productivity parameters are also noteworthy. The number of drug intakes because of a new flare-up of urticaria was considerably lower in the levocetirizine group than in the placebo group (approximately 10 times lower: 2.5 vs 25.9). Patients treated with levocetirizine also improved their work productivity during the study period. ${ }^{47}$

In a six-week double-blind, placebo-controlled study we conducted, the efficacy of levocetirizine was assessed in a population of 106 patients with chronic idiopathic urticaria at a daily dosage of $5 \mathrm{mg} .{ }^{48}$ The investigation included an assessment of symptoms (pruritus; number, size and spread of the wheal lesions; number of new flare-ups, with scores of 0 to 3 according to severity) using TSS and VAS (Visual Analogue Scale at $10 \mathrm{~cm}$ ); the assessment was then verified through a 5-question survey on QoL changes. ${ }^{48}$ As early as the first three weeks, the study confirmed levocetirizine to be markedly more effective than placebo in reducing the scores of the considered scales (TSS, VAS, QoLQ). ${ }^{48}$ At the end of treatment $53 \%$ of the patients who had received levocetirizine reported total disappearance of symptoms, reduced itching intensity $(85 \%)$, reduced number and spread of the wheal lesions (79\% and $75 \%$ respectively) in significant percentages compared to subjects treated with placebo. Moreover, the beneficial effects of the treatment persisted up to seven days after the treatment suspension. ${ }^{48}$

An analysis of costs in 294 patients with chronic idiopathic urticaria treated with levocetirizine vs placebo has recently confirmed that, in terms of work and social costs, levocetirizine allows monthly savings for $€ 91.93$ per individual patient on the costs of medical investigations, combined therapies, days of hospital stays and loss of work productivity resulting in treatment costs of more than $€ 1$ per day. ${ }^{49}$

\section{Conclusions}

Levocetirizine is a newly developed selective H-1 antagonist and is the R-enantiomer or active isomer of the racemate cetirizine. Its small volume of distribution, smaller even than that of cetirizine, confers improved safety because of its lesser passage through the blood-brain barrier and low cerebral receptor binding. The drug's safety is confirmed by the absence of cardiotoxic effects and the mild nature of the reported adverse reactions (fatigue, headache, dizziness, and dry mouth) during treatment, which do not generally interfere with the patient's well being even in the case of chronic treatment. 
According to the examined studies, levocetirizine represents a potent, consistent and long-lasting medication for the treatment of both intermittent and persistent allergic rhinitis and chronic idiopathic urticaria. In patients with allergic rhinitis, treatment with levocetirizine at a dose of $5 \mathrm{mg}$ daily produced a significant decrease in sneezing, rhinorrhea, itching nose, itching eyes and nasal congestion. Also the efficacy of levocetirizine to treat chronic idiopathic urticaria was widely demonstrated. In particular, a long-term treatment with this antihistamine can improve the quality of life and symptoms and decrease the overall costs of allergic diseases; these are some of the key criteria for the successful treatment of chronic diseases.

\section{Disclosure}

The authors report no conflicts of interest in this work.

\section{References}

1. Day JH, Ellis AK, Rafeiro E. Levocetirizine: a new selective H-1 receptor antagonist for use in allergic disorders. Drugs Today. 2004;40:415-421.

2. Gillard M, Van der Perren C, Moguilevsky N, Massingham R, Chatelain P. Major role for the carboxylic function of cetirizine and levocetirizine in their binding characteristics to human $\mathrm{H}-1$ histaminereceptors. Inflamm Res. 2002;51:S79-S80.

3. Gillard M, Chatelain P. Changes in $\mathrm{pH}$ differently affect the binding properties of histamine H1 receptor antagonists. Eur J Pharmacol. 2006;530:205-214.

4. Simons FE. Advances in H-antihistamines. $N$ Engl J Med. 2004;351:2203-2217.

5. Triggiani M, Gentile M, Secondo A, et al. Histamine induces exocytosis and IL-6 production from human lung macrophages through interaction with H receptors. J Immunol. 2001;166:4083-4091.

6. Triggiani M, Giannattasio G, Balestrieri B, Loffredo S, Forte V, Granata F. Phenotypical and functional heterogeneity of human lung macrophages. Clin Exp Allergy Rev. 2004;4:129-134.

7. Giustizieri ML, Albanesi C, Fluhr J, Gisondi P, Norgauer J, Girolomoni G. H histamine receptor1 mediates inflammatory responses in human keratinocytes. J Allergy Clin Immunol. 2004;114:1176-1182.

8. Gutzmer R, Wittmann M, Kapp A, Werfel T. Direct immunomodulatory effects of levocetirizine on lymphocytes. Paris, France: Proceedings of the XXII Congress of the European Academy of Allergy and Clinical Immunology; 2003.

9. Ying S, Meng Q, Kay AB. The effect of levocetirizine on histamine and cytokine-induced upregulation of eotaxin by endothelial cells. Naples, France: Proceedings of the XXI Congress of the European Academy of Allergy and Clinical Immunology; 2001.

10. Thomson L, Blaylock MG, Sexton DW, Campbell A, Walsh GM. Cetirizine and levocetirizine inhibit eotaxin-induced eosinophil transendothelial migration through human dermal or lung microvascular endothelial cells. Clin Exp Allergy. 2002;32:1187-1192.

11. Wu P, Mitchell S, Walsh GM. A new antihistamine levocetirizine inhibits eosinophil adhesion to vascular cell adhesion molecule-1 under flow conditions. Clin Exp Allergy. 2005;35:1073-1079.

12. Hasala H, Janka-Junttila M, Moilanen E, Kankaanranta H. Levocetirizine and cytokine production and apoptosis of human eosinophils. Allergy Asthma Proc. 2007;28:582-591.
13. Benedetti MS, Plisnier M, Kaise J, et al. Absorption, distribution metabolism and excretion of (14C) levocetrizine, the R-enantiomer of cetirizine in healthy volunteers. Eur J ClinPharmacol. 2001;57:571-582.

14. Marshall GD Jr. Therapeutic options in allergic disease: antihistamines as systemic antiallergic agents. J Allergy Clin Immunol. 2000;106:S303-S309.

15. Wang KY, Arima N, Higuchi S, et al. Switch of histamine receptor expression from $\mathrm{H} 2$ to $\mathrm{H} 1$ during differentiation of monocytes into macrophages. FEBS Lett. 2000;473:345-348.

16. Triggiani M, Petraroli A, Loffredo S, et al. Differentiation of monocytes into macrophages induces the upregulation of histamine $\mathrm{H} 1$ receptor. J Allergy Clin Immunol. 2007;119:472-481.

17. Tillement JP. A low distribution volume as a determinant of efficacy and safety for histamine (H1) antagonists. Allergy. 1995;50:12-16.

18. Verster JC, Volkerts ER, van Oosterwijck AW, et al. Acute and subchronic effects of levocetirizine and diphenhydramine on memory functioning, psychomotor performance, and mood. J Allergy Clin Immunol. 2003;111:623-627.

19. Verster JC, de Weert AM, Bijtjes SI, et al. Driving ability after acute and sub-chronic administration of levocetirizine and diphenhydramine: a randomized, double-blind, placebo-controlled trial. Psychopharmacology. 2003;169:84-90.

20. Hindmarch I, Johnson S, Meadows R, Kirkpatrick T, Shamsi Z. The acute and sub-chronic effects of levocetirizine, cetirizine, loratadine, promethazine and placebo on cognitive function, psychomotor performance, and weal and flare. Curr Med Res Opin. 2001;17:241-255.

21. Gandon JM, Allain H. Lack of effect of single and repeated doses of levocetirizine, a new antihistamine drug, on cognitive and psychomotor functions in healthy volunteers. Br J Clin Pharmacol. 2002;54:51-58.

22. Potter PC. Levocetirizine is effective for symptom relief including nasal congestion in adolescent and adult (PAR) sensitized to house dust mites. Allergy. 2003;58:893-899.

23. Hulhoven R, Rosillon D, Letiexhe M, Meeus MA, Daoust A, Stockis A. Levocetirizine does not prolong the QT/QTc interval in healthy subjects: results from a thorough QT study. Eur J Clin Pharmacol. 2007;63:1011-1017.

24. Klimek L, Hundorf I. Levocetirizine in allergic diseases: an open multicentre practice study of efficacy and tolerability. Allergologie. 2002;25:S1-S7.

25. Leynadier F, Mees K, Arendt C, Pinelli ME. Efficacy and safety of levocetirizine in seasonal allergic rhinitis. Acta Otorhinolaryng Belg. 2001;55:305-312.

26. Potter PC. Levocetirizine is effective for symptom relief including nasal congestion in adolescent and adult sensitized to house dust mites. Allergy. 2003;58:893-898.

27. Horak F, Stubner UP, Zieglmayer R, Moser M, Kavina A, Englbrecht W. Effect of levocetirizine and loratadine on symptoms relief in house dust mite allergic patients exposed to allergen in the Vienna Challenge Chamber. Allergy. 2001;56(Supp1 68):201-202.

28. Passalacqua G, Guerra L, Compalati E, et al. Comparison of the effects in the nose and skin of a single dose of desloratadine and levocetirizine over 24 hours. Int Arch Allergy Clin Immunol. 2004;135:143-147.

29. Deruaz C, Leimgruber A, Berney M, Pradervand E, Spertini F. Levocetirizine better protects than desloratadine in a nasal provocation with allergen. J Allergy Clin Immunol. 2004;114:838-844.

30. Ciprandi G, Cirillo I, Vizzaccaro A, Tosca MA. Levocetirizine improves nasal obstruction and modulates cytocine pattern in patients with seasonal allergic rhinitis: a pilot study. Clin Exp Allergy. 2004;34:958-964.

31. Day JH, Briscoe MP, Rafeiro E, Ratz JD. Comparative clinical efficacy, onset and duration of action of levocetirizine and desloratadine for symptoms of seasonal allergic rhinitis in subjects evaluated in the environmental exposure unit (EEU). Int J Clin Pract. 2004;58:109-118. 
32. Horak F, Zieglmayer PU, Zieglmayer R, Kavina A, Lemell P. Levocetirizine has a longer duration of action on improving total nasal symptoms score than fexofenadine after single administration. $\mathrm{Br} \mathrm{J}$ Clin Pharmacol. 2005;60:24-31.

33. Larbig M, Burtin B, Martin L, Stamm H, Luettig B, Hohlfeld JM, Krug N. Facial termography is a sensitive tool to determine antihistaminic activity: comparison of levocetirizine and fexofenadine. $\mathrm{Br} \mathrm{J}$ Clin Pharmacol. 2006;62:158-164.

34. Bousquet J, Van Cauwenberge P, Khalthaev N. Allergic rhinitis and its impact on asthma. J Allergy Clin Immunol. 2001;108:S147-S334.

35. Bachert C, Bousquet J, Canonica GW, et al. XPERT: levocetirizine long term treatment in patients suffering from persistent allergic rhinitis. Allergy. 2003;58(Suppl 74):77.

36. Bousquet J, Demarteau N, Mullol J, et al; XPERT study group. Costs associated with persistent allergic rhinitis are reduced by levocetirizine. Allergy. 2005;60:788-794.

37. Lee DK, Gray RD, Wilson AM, Robb FM, Soutar PC, Lipworth BJ. Single and short term dosing effects of levocetirizine in adenosine monophosphate brochoprovocation in atopic asthma. $\mathrm{Br} \mathrm{J} \mathrm{Clin}$ Pharmacol. 2004;58:34-39.

38. Hide M, Francis DM, Grattan CE, Hakimi J, Kochan JP, Greaves MW. Autoantibodies against the high affinity $\mathrm{IgE}$ receptor as a cause of histamine release in chronic urticaria. N Engl J Med. 1993;328:1599-1604.

39. Asero R, Tedeschi A, Coppola R, et al. Activation of the tissue factor pathway of blood coagulation in patients with chronic urticaria. J Allergy Clin Immunol. 2007;119:705-710.

40. Asero R, Tedeschi A, Riboldi P, Griffini S, Bonanni E, Cugno M. Severe chronic urticaria is associated with elevated plasma levels of D-dimer. Allergy. 2008;63:176-180.

41. Grant JA, Riethuisen JM, Moulaert B, DeVos C. A double-blind, randomized, single-dose, crossover comparison of levocetirizine with ebastine, fexofenadine, loratadine, mizolastine, and placebo: suppression of histamine-induced wheal-and-flare response during 24 hours in healthy male subjects. Ann Allergy Asthma Immunol. 2002;88:190-197.
42. Devalia JL, De Vos C, Hanotte F, Baltes E. A randomized, double-blind, crossover comparison among cetirizine, levocetirizine, and UCB 28557 on histamine-induced cutaneous responses in healthy adult volunteers. Allergy. 2001;56:50-57.

43. Denham KJ, Boutsiouki P, Clough GF, Church MK. Comparison of the effects of desloratadine and levocetirizine on histamine-induced wheal, flare and itch in human skin. Inflamm Res. 2003;52:424-427.

44. Purohit A, Melac M, Pauli G, Frossard N. Twenty-four hour activity and consistency of activity of levocetirizine and desloratadine in the skin. Br J Clin Pharmacol. 2003;56:388-394.

45. Frossard N, Strolin-Benedetti M, Purohit A, Pauli G. Inhibition of allergen-induced wheal and flare reactions by levocetirizine and desloratadine. Br J Clin Pharmacol. 2008;65:172-179.

46. Kapp A, Wedi B. Chronic urticaria: clinical aspects and focus on a new antihistamine, levocetirizine. J Drugs Dermatol. 2004;3:632-639.

47. Kapp A, Pichler WJ. Levocetirizine is an effective treatment in patient suffering from chronic idiopathic urticaria: a randomised doubleblind placebo controlled parallel multicentric study. Int J Dermatol. 2006;45:469-474.

48. Nettis E, Colanardi MC, Barra L, Ferrannini A, Vacca A, Tursi A. Levocetirizine in the treatment of chronic idiopathic urticaria: a randomized double-blind placebo controlled study. Br J Dermatol. 2006;154:533-538.

49. Kapp A, Demarteau N. Cost-effectiveness of levocetirizine in chronic idiopathic urticaria: a pooled analysis of two randomised controlled trials. Clin Drug Invest. 2006;26:1-11. 
